\title{
MATERNAL AND FETAL OUTCOME FOLLOWING SEVERE ANAEMIA IN PREGNANCY: RESULTS FROM NOBEL MEDICAL COLLEGE TEACHING HOSPITAL, BIRATNAGAR, NEPAL.
}

\section{Ram Hari Ghimire and Sita Ghimire}

\begin{abstract}
:
Background: anaemia is a major contributor to maternal death in developing countries. Since it reduces resistance to blood loss, death may occur from bleeding associated with normal delivery.
\end{abstract}

Objective: To explore the association between anaemia and maternal and perinatal complications.

Study Design: Retrospective cohort study.

Materials and Methods: 100 pregnant women admitted for delivery and having severe anaemia were studied and compared with 100 non anaemic women matched for age, parity, and gestational age. Adverse outcomes analysed were: pregnancy induced hypertension, Postpartum haemorrhage hypertension, Abruptio Placenta, Infection, Maternal Mortality, Low Birth Weight, and Perinatal mortality.

Results : Compared to nonexposed women, exposed women had an increased risk of pregnancy induced hypertension with odds ratio of 5.06 . Postpartum haemorrhage, incidence of wound infection,Intermediate care unit admission were statistically significant in exposed group .However there was no significant difference in maternal mortality among study group.APGAR score $<7$ in 5 minutes was $18 \%$ in exposed group and $5 \%$ in non exposed group ( $\mathrm{p}=0.0039$ ). Intrauterine fetal death was $6 \%$ in cases and none of respondants from control group had Intrauterine fetal death $(\mathrm{p}=0.0128)$. Frequency of low birth weight was $22 \%$ in exposed group and $9 \%$ in non exposed $\operatorname{group}(\mathrm{p}=0.011)$.

Conclusions: The burden of anemia in pregnant population is still high in eastern region of Nepal. Severe anemia in pregnancy carries significant risk to mother and fetus. Hence preventive measures need to be implemented at community level. Public awareness regarding pre-pregnancy hemoglobin status and importance of antenatal checkup relating with maternal and fetal adverse pregnancy outcome should be initiated.

Key words: Severe anemia in pregnancy, maternal outcome, fetal outcome, Nepal

Introduction

Anaemia is the commonest medical disorder in pregnancy. It is specially more common in developing countries, because of poor nutritional and high prevalence of parasitic infestation. ${ }^{1,2}$ Anaemia is defined by WHO as "haemoglobin level less than 10 gms 
percentage in pregnancy. It is divided into three degree viz mild degree (9-10.9 gm \%), moderate degree (7.0- $8.9 \mathrm{gm} \%$ ) andf severe degree (less than $7.0 \mathrm{gm} \%)^{5}$

Prevalence of anaemia among pregnant women in developing countries average $56 \%$ with a range of $35 \%$ to $100 \%$ among various region of the world. ${ }^{3}$ A study of Dreyfuss et al showed that the prevalence of anaemia to be $73 \%$ in the plaIn of Nepal with $88.9 \%$ of the women infected with helminths. ${ }^{4}$ Anaemia in pregnancy is considered one of the major risk factors contributing to maternal death in developing countries. ${ }^{6}$ Haemorrhage, eclampsia and infection being the three major causes of maternal death in Nepal. ${ }^{7}$

An association of anaemia with adverse maternal outcome such as puerperal sepsis, antepartum haemorrhage, postpartum haemorrhage and maternal mortality is no longer a debatable issue. ${ }^{8,9,10}$ Pre conceptional counseling for carrying pregnancy minimum $8 \mathrm{gm}$ percent haemoglobin must be present. That is why early diagnosis and treatment of anaemia is very important. Though there are many studies on anaemia in pregnancy in Nepal showing a high prevalence but relatively few studies has been done in the maternal and fetal outcome.

Keeping all this in view, this study was conducted to find out maternal and fetal outcome after severe anaemia in pregnancy.

\section{Materials and methods}

This study was carried out in obstetric and gynaecology department of Nobel Medical College from 15 April 2011 to 14 April 2012. All women admitted for delivery and having a haemoglobin level less than $7 \mathrm{gm} \%$ were studied. Control was selected from the every second woman admitted for delivery and having matching criteria age, parity, and period of gestation and whose haemoglobin level is more than $11 \mathrm{gm} \%$. The observation was made for maternal complications like anti partum haemorrhage, $\mathrm{PPH}$, pregnancy induced hypertension, infection, and maternal death. Perinatal outcome like small for gestational age, low birth weight, APGAR score, and Perinatal Deaths were also noted.

Data were entered and analysed using SPSS 17 and Epi-Info 7. The odds ratio was calculated by contingency table (Tables 1,2 , $3)$.

\section{Results}

The total number of patients delivered during the study period were 2754 live births.Incidence of severe anemia was found to be $7 . \%$. The mean haemoglobin of cases were $6.2 \mathrm{gm} \%$.

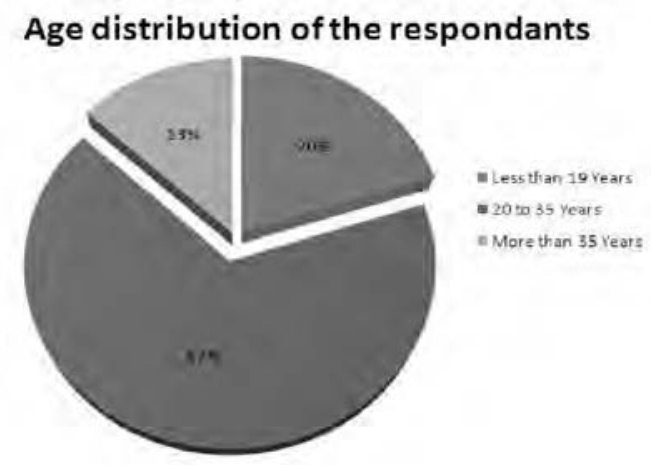

Most of the respondents were from the age groups $20-35$ Years i.e. $67 \%$ and $20 \%$ were from the age group $<19$ years of age.

Though primigravida were common in total no of deliveries, severe aneamia was found to be more common in multi gravida.

In this study it was revealed that $60 \%$ of the respondants were multigravida. 


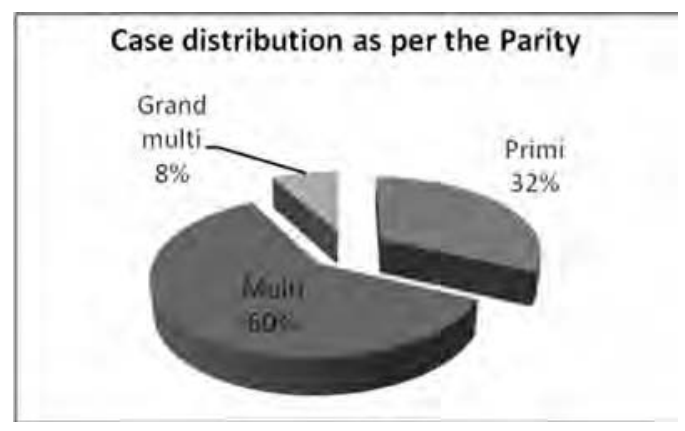

Majority of respondants were unbooked in both the exposed and non exposed group reflecting the public awareness regarding antenatal check up during pregnany in eastern region of Nepal.

Although all complications were more common in exposed group,but statistical

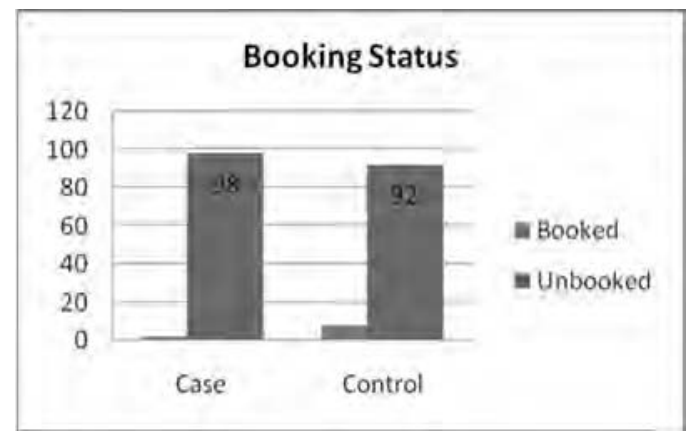

significant differences were observed in Pregnancy induced hypertension, postpartum haemorrhage, infection and in terms of intensive care admission, APGAR score, in utero death and low birth weight.

\section{Discussion}

In Nepal it is commonly met patients with anemia in late pregnancy without prior antenatal care. The same is evidient in this study where a vast majority of respondants were unbooked.Jallel $\mathrm{R}$ and Khan A found that $69.9 \%$ pregnant women were anemic and $4.8 \%$ were severly anemic. ${ }^{11}$ Marhatha $\mathrm{R}$
5 reported $2.2 \%$ severly anemic pregnant women in Kathmandu which is comparable to our study $3.8 \%$ This study has demonstrated a causal relationship between severe anemia and various maternal and perinatal complication.

\begin{tabular}{|c|c|c|c|c|}
\hline \multicolumn{5}{|c|}{ Table 1: Maternal Complications } \\
\hline $\begin{array}{c}\text { Complication } \\
\text { s }\end{array}$ & $\begin{array}{c}\text { Case } \\
\%\end{array}$ & $\begin{array}{c}\text { Contr } \\
\text { ol \% }\end{array}$ & $\begin{array}{c}\text { Odd } \\
\text { Ratio }\end{array}$ & P-Value \\
\hline $\begin{array}{c}\text { Pregnancy } \\
\text { induced } \\
\text { hypertension }\end{array}$ & 36 & 10 & 5.06 & 0.00001 \\
\hline $\begin{array}{c}\text { Post Partum } \\
\text { Heamorahhge }\end{array}$ & 14 & 5 & 3.09 & 0.0299 \\
\hline $\begin{array}{c}\text { Abruptio } \\
\text { Placentae }\end{array}$ & 3 & 1 & 3.06 & 0.3124 \\
\hline $\begin{array}{c}\text { Infection } \\
\text { Mode of } \\
\text { Delivery C/S }\end{array}$ & 22 & 5 & 5.35 & 0.0004 \\
\hline ICU admission & 14 & 1 & 16.11 & 0.0004 \\
\hline $\begin{array}{c}\text { Maternal } \\
\text { Death }\end{array}$ & 3 & 0 & 16.61 & 0.0111 \\
\hline Booked & 2 & 8 & 0.23 & 0.0511 \\
\hline Unbooked & 98 & 92 & 4.26 & 0.0515 \\
\hline
\end{tabular}

We have found that pregnancy induced hypertension is five times more common in severe anemia.

In our study, significant proportion of patients had postpartum haemorrhage. Wandabwa $\mathrm{J}$ has also indicated severe anemia as a predictor of postpartum haemorrage. ${ }^{12}$ We also observe that severe anemic patients developed wound infection in $16 \%$ cases, which is higher than study done by Riffat Jallelet al where it is only $7.8 \%$ but it is very minimal in comparision with study done by Dare FO and colleague $69.2 \%{ }^{13}$ 
We found severe anemia significantly increases the risk of neo-natal complication. In this study the prevalence pre term delivery was $34 \%$ which is comparable with study done in south Africa. ${ }^{14}$ Regarding APGAR score we observed $18 \%$ of neo-nate had less than seven in five minutes in women with haemoglobin level of $<7 \mathrm{gm} \%$, which is higher than $11.2 \%$ of Jallel $\mathrm{R}$ and Khan A. ${ }^{11}$ Lone FW and colleagues ${ }^{15}$ have observed risk of low birth weight and small for gestational age in new born,In severely anemic women it was 4.22 and 1.9 in compared to non anemic women, which is comparable to 2.85 and 2.87 of our study. Geelhoed D had also observed similar result 16

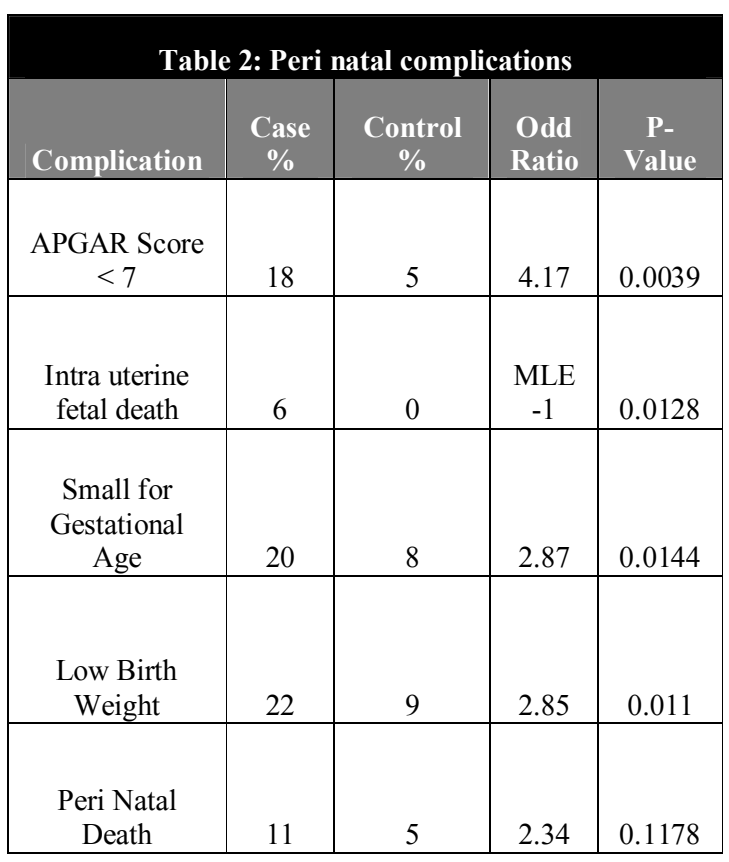

This study had shown significant association of maternal anemia with maternal and fetal complication. However this study included only those women who came to our hospital and were aware of hospital delivery. So ,the results cannot be generalized in the country. Various strategies have been tried in the world including Nepal where cooking in iron pots was tried and showed a significant reduction in iron deficiency anemia in women . ${ }^{17}$ To improve the scenario of anemia, iron intake in the form of dietary supplement along with prescribing iron tablets in routine antenatal check up have been suggested.

\section{Conclusion}

The burden of anemia in pregnant population is still high in eastern region of Nepal,as it carries significant risk to mother and fetus. Hence preventive measures need to be implemented at community level. Public awareness regarding pre-pregnancy hemoglobin status and importance of antenatal checkup relating with maternal and fetal adverse pregnancy outcome should be initiated.

\section{References}

1. Guidotti RJ. Anaemia in pregnancy in developing countries. Br J Obstet Gynaecol. 2000; 107: 437- 8 .

2. Van den Broek N. Anaemia in pregnancy in subSaharan countries. Eur J Obstet Gynecol Reprod Biol. 2001; 96: 4- 6.

3. World health organization. The prevalence of anemia in women: a tabulation of available information, $2^{\text {nd }}$ Ed., Geneva: WHO, 1992.

4. Dreyfuss ML, stoltzus RJ, sherestha JB, Pradhan EK, LeClerq SC, Khartry SK et al. Hookworms, Malaria and vitamins A Deficiency contribute to anemia and iron deficiency amomg pregnant women in the plains of Nepal. Journals of nutrition 2000; 130(10): 2527-36

5. Marhatta R. Study of anemia in pregnancy and its outcome in Nepal Medical College Teaching Hospital, Kathmandu, Nepal. Nepal Med Coll J 2007;9:270- 4 .

6. AbouZahr C, Royston E. Maternal mortality. A Global factbook. World health organization, geneva, 1991. 
7. His majesty's government, Nepal/world health organization. Research report on prevention of maternal mortality in hospitals of Nepal, Kathmandu, 1992.

8. Roy S, chakrawarty PS,. Maternal and perinatal outcome in severe anemia. J Obstet Gynae Ind 1992;42: 743-50.

9. Bondevik GT, Ulstein M, Lie RT, Rana G, K vale G. the prevalence of anemia in pregnant nepali women- a study in Kathmandu Acta obstet gynecol Scand 2000;79(5): 341-9

10. Ulstein M, Rana G, Yangzom K, Gurung R, Karki A , Gurung $\mathbf{G}$ et al. some fetal and pregnancy parameters in Nepal. Acta Obstet Gynecol Scand 1998;67 :47-52

11. Riffat jaleeland Ayesha Khan. Journal of surgery Pakistan(international) 13 (4)OctoberDecember 2008.

12. Wandabwa J, Dovle $\mathbf{P}$, Todd J, Ononge $\mathbf{S}$, Kiondo P. Risk factors for severe postpartum hemorrhage in Mulago Hospital, Kampala, Uganda. East Afr Med J 2008;85:64-71.

13. Dare FO, Bako AU, Ezechi OC. Puerperal sepsis: a preventable postpartum complication. Trop Doct 1998;28:92-95.

14. Suria BK, ehsanul H, Charles. Prevalence of anemia in pregnancy Greytown, south Africa, Trop J Obstet Gynecol 2006; 32 :3-7.

15. Lone FW, Qureshi RN, Emanuel F. Maternal anaemia and its impact on perinatal outcome. Trop Med Int Health 2004;9:486-90

16. Geelhoed D. Maternal and fetal outcome after severe anemia in pregnancy in rural Ghana. Acta Obstet Gynecol Scand 2006;85:49-55.

Geerligs PP, Brabin B, Mkumbwa A, Broadhead R, Cuevas LE. The effect on haemoglobin of the use of iron cooking pots in rural Malawian households in an area with high malaria prevalence: a randomized trail. Trop Med Int health. 2003;8 (4); 310-5

Address of correspondence: Ram Hari Ghimire, Lecturer, Department of Internal Medicine Nobel Medical College, Biratnagar-5, E-mail: drsita42@yahoo.com 